\section{UTOPIA, HISTÓRIA E GENOCÍDIO}

\section{Um panorama de sonhos fracassados}

\author{
Alexandre Gomide Xavier \\ Graduado em Filosofia \\ Universidade Católica de Brasília
}

\section{RESUMO}

Seres humanos são seres utópicos. Estamos sempre em busca de sonhos capazes de solucionar os problemas do mundo a dar fim ao sofrimento humano. Contudo durante a história vimos que ao tentar realizarmos nossas utopias acabamos criando um grande campo de extermínio. O seguinte artigo quer discutir se é possível buscar algum fundamento ético livre de utopias ideológicas e qual o porquê de nossas utopias sempre desembocar em caminhos tortuosos.

Palavras-chaves: História, Utopia, Revolta, Genocídio, Humanismo.

\begin{abstract}
Humans beings are utopic being. Our life is a searching for dreams able to fix the world's problems and ending human duffering. Yet we can see that during the course of history we have created a huge annahilation. This paper wants to bring a dialogue asking how is possible get a ethics principle free of utopic ideology and why our utopic dreams always goes for dark paths.
\end{abstract}

Key-Words: History, Utopy, Revolt, Genocide, Humanism
Introdução

Utopias, sonhos dotados de uma abstração e beleza moral fazem parte do desejo da humanidade, são vislumbradas como um guia ou como um caminho possível para alcançar, através de uma práxis, um mundo perfeito, unificado, uma sociedade perfeita. As utopias aparecem como estruturas fundamentais de ideologias. Porém, o que foi experimentado, no decorrer da história, principalmente, em grandes períodos de conturbações políticas, foi inúmeros massacres genocidas em busca da realização de uma ideologia.

A história tem se mostrado um verdadeiro cemitério. No presente artigo, tem-se a intenção de se debruçar sobre os aspectos que estão por trás desse movimento subjetivo da consciência humana que leva a utopia como justificação de assassinatos, ou seja, qual seria o álibi que torna legítimo os assassinatos em nome das utopias. É necessário, então, buscar, no íntimo do ser humano, de seus sentimentos e aspirações, explicações capazes de suscitar o apego fanático por perseguir tais ideias, logo é necessário analisar as consequências e, através de um prognóstico, encontrar uma maneira de direcionar o pensamento filosófico a uma ética que não tenha como 
objetivo a utopia, mas que busque a possibilidade de um humanismo que não se apoie em um mundo fabricado por meio de utopias ideológicas, ou seja, uma cidade perfeita ou sistema perfeito.

Em outras palavras, o mundo das utopias é um mundo que precisa ser fabricado, que nega este mundo para a construção de um novo mundo. A discussão é: Como é possível às utopias terem justificado tantos massacres? O que possibilita $\mathrm{o}$ fanatismo às ideologias $\mathrm{e}$ como ele movimenta uma busca histórica? Se formos responder tais questões, logo podemos, também, traçar um prognóstico que aponta para uma ética do desapego às utopias políticas que guiam a um possível humanismo.

\section{A esperança}

"Toda a desgraça dos homens vem da esperança que os arranca do silêncio da cidadela, que os atira às muralhas à espera da salvação."

(CAMUS, 2011:46)

No campo onde as utopias se sustentam, há sempre o sentimento de esperança. Mas seria possível indagar como a esperança faz esse movimento, pois claramente não estamos falando da esperança cotidiana de um emprego novo, de melhorar de uma gripe. Falamos, sim, da esperança que visa à universalidade e à salvação da humanidade, esperança com caráter religioso; e não propriamente uma religião, contudo, um caráter messiânico engendrado em toda ideia.

Albert Camus (1913-1960) em seus ensaios $O$ mito de Sísifo e $O$ homem revoltado e alguns escritos de E. Cioran (1911-1995) desenhará um guia para nosso empreendimento filosófico. Primeiramente, o movimento que a esperança traz é um sentimento que tira o homem de seu eixo existencial e aponta para uma vida que se mostra melhor e superior a esta aqui, ou seja, a esperança é niilista. Tanto o cristianismo quanto as ideologias descrevem a cidade perfeita, onde há somente o bem e há apenas espaço para um modelo de vida. Logo, tornar-se-ia necessária que, neste movimento unilateral, seja suprimida toda diversidade. A primeira noção da esperança é abordada juntamente com o que Camus chama de suicídio filosófico, ação que consiste em dar um salto fé. Durante toda história da filosofia, se deram saltos os quais sempre preservaram a esperança, pois, diante do abando existencial, do absurdo, segundo o filósofo franco-argelino, nunca pensaram a possibilidade ou as consequências da consciência que se separa do mundo (CAMUS, 2012, p. 43-62). 
Neste embate, quando se debruçavam e se encontravam face a face da condição humana extraiam e ofereciam a nós uma resposta rápida e confortável: a salvação por meio do salto. Seja essa resposta pela fé ou por algum outro artifício. Já no seu segundo ensaio há, então, mais claro a ideia que fará parte da nossa reflexão sobre as ideologias. Se, no primeiro ensaio, a questão era sobre a individualidade, é sabido que o corpo coletivo é sempre formado de vários indivíduos, a questão é: Como a esperança pode legitimar os assassinatos e causar mais mal no mundo?

Ora, segundo Camus (CAMUS, 2011, p. 86-90), há uma passagem de uma visão de mundo metafísico a uma visão histórica e com Nietzsche e, anteriormente, com Hegel onde tem seu apogeu, sua ascensão. Porém, se para Nietzsche o cristianismo era niilista por acreditar em uma vida ideal, que subjuga a vida mundana, onde os valores são nada humanos e, por tal motivo, acabam causando um espírito de ressentimento e de degradação de afirmação da vida, são com Nietzsche que o niilismo foi levado as suas últimas consequências. Por outro lado, abriu também espaço para o reforço de uma percepção totalmente histórica da humanidade que já rondava a filosofia.

Esse caráter de historicidade é propriamente onde destronamos Deus, primeiramente, o julgamos como nosso igual, ou seja, o rebaixamos a ser condenado sobre o viés da história assim como nós. Deus, primeiramente, é rebaixado e depois ocorre o deicídio, porém, das consequências dessa morte divina, há uma lacuna que é nosso desejo de unidade. Desejo de unidade oriundo de uma revolta metafísica. (CAMUS, 2011, p. 37).

Se na revolta eliminamos Deus, ainda, assim sentimos falta do carinho e da aprovação paterna, como um filho que recém largou o ambiente familiar. $\mathrm{O}$ desejo de unidade é a nossa vontade e tensão ao universal, a verdade e a reconciliação do homem, ou melhor, da humanidade com o mundo. Esse desejo é a vontade de suprimir um mundo totalmente móvel, devir, em algo estático onde se superem, principalmente, as mudanças como também a morte, ou seja, a vontade de afirmar esta vida, de não abandoná-la, a aspiração à unidade é, também, o instinto da explicação cabal de toda totalidade e realidade humana, daí a reconciliação do ser humano: consciência e mundo.

As utopias ideológicas, oriundas do marxismo, acabam por substituir a religião, e se tornam objeto de culto. Nesse ponto a esperança que guia a negação da vida, no mesmo movimento niilista que o cristianismo realizava, é exercida pela fé da política, da história como um fim. E sua 
glória se firma em Marx. "Ao divinizar a história para desacreditar em Deus, o marxismo só conseguiu tornar Deus mais estranho e mais obsedante, Pode-se sufocar, tudo no homem, salvo sua necessidade de absoluto." (CIORAN, 1994, p. 37). Segundo Camus, foi na Rússia, que houve a grande reviravolta do empreendimento da metafísica absorvida pela história e não nos outros empreendimentos totalitários que representavam um dinamismo primitivo fadado ao fracasso, pois os empreendimentos fascistas tinham em seu movimento, não a pretensão de uma teleologia culminada na moral e a unidade abarcada pela filosofia, pelo contrário, os avanços fascistas eram culminados na ideia de dominação com arcabouço na ideia da destruição e da honra militar que faziam parte de um jogo de tudo ou nada, onde quem não era superior para dominar deveria ser atirado ao seio da destruição. Todo fascismos faziam parte apenas de um plano provinciano de conquista que, com Hitler, acabou se desviando para uma tentativa de um império, sendo assim, careciam do caráter divinatório das utopias ideológicas. Era apenas um teste que deveria atestar que aquele que se propõe a dominar, se não ganhar também não merece viver. $\mathrm{O}$ fim era apenas $\mathrm{o}$ apocalipse pelo apocalipse (CAMUS,
2011, p. 218). O fruto de uma alta ressentida e não revoltada ${ }^{1}$.

Os seguidores de Marx estabeleceram uma relação de verdade com as previsões descritas pela teoria marxista, já que podiam ser controladas e possuíam características de curto prazo. $\mathrm{O}$ que fizeram foi estabelecer uma relação de profecia, a profetização da teoria se apoia no mesmo campo da religião: a falta de provas. Daí, ainda segundo Camus, mesmo que as previsões fossem fracassadas, a profecia continua a ser empreendimento da esperança. (CAMUS, 2011, p. 218-220). Aqui tratamos rapidamente $\mathrm{o}$ plano psicológico, mas o que acontece quando esse campo se mistura com o campo da política? Para onde guiam a esperança, o desejo de unidade e juntamente com o messianismo político?

\section{O messianismo}

"Mesmo quando se afastado da religião, o homem permanece submetido a ela; esgotando-se em forjar simulacros de deuses." (CIORAN, 2011:13)

Acontece que o comunismo partiu, mesmo sem saber, de uma mesma lógica

\footnotetext{
${ }^{1}$ Caso conste aqui o que seria a diferença entre os dois esclareço que abordaremos a revolta neste trabalho.
} 
Cristã. O cristianismo foi o introdutor da ideia de final da história, não havia antes dele a noção linear de uma história, logo o movimento utópico só faz sentido, também, a partir da história do cristianismo. $\mathrm{O}$ primeiro discurso ideológico é definitivamente o paraíso. Entre outras palavras, o pensamento cristão trouxe a noção de que a vida é uma sucessão de acontecimentos em curso ao um fim último "no decorrer da qual o homem ganha sua salvação ou merece seu castigo." (CAMUS, 2011, p. 221).

No movimento da negação da divindade de Cristo, pela filosofia e influência do pensamento científico, o ocidente ainda preservou sua vontade de unidade, então nesta passagem, já suscitada nesta investigação, do religioso e metafísico a uma identidade totalmente história, há um movimento de busca de divinização do homem e da ideia de progresso. Na perspectiva de Camus, Marx substitui a vontade divina pela ideia do progresso, isso significa dizer que na visão marxista a história tendia a um fim último capaz de acabar com todo o antagonismo vivido. Onde seríamos levados a uma sociedade sem classes e tudo se reconciliaria em uma justiça e moralidade congelada (CAMUS, 2011, p. 226).

A definição mais própria então seria de determinismo, pois o pensamento aqui não é negado, é transfigurado em absoluto do plano do pensamento, da utopia para a realidade exterior. Tal concepção mistura parte do ponto que a humanidade é só história e, necessariamente, história dos meios de produção, logo, é preciso situar a origem do homem no nível econômico e tratá-lo apenas como relações sociais. O social não permite o ser humano como criador, mas apenas como fruto do meio social e, por isso, a transcendência não tem espaço no pensamento utópico ideológico. Se antes tínhamos a utopia de uma salvação após a morte, agora, a projetamos para o futuro, ou seja, na História. Daí, temos a primeira evidência de que as utopias podem justificar os assassinatos. Não é pela falta de uma busca moral ou pela falta de justiça como no caso dos regimes fascistas, mas por causa de um guia único de moralidade, de um ato messiânico de dizer qual o fim que a história deve chegar. A utopia trata os homens apenas como rebanhos, ou seja, é um Pai autoritário que escolhe o casamento do filho por puro interesse sem ao menos lhe consultar a sua vontade. "Marx acreditou que os fins históricos, pelo menos, se revelariam morais e racionais. Nisto reside sua utopia." (CAMUS, 2011, p. 243).

Outro problema oriundo das utopias é que: a reconciliação do ser humano com a história dos antagonismos sociais exige outro mundo aqui e agora, um mundo 
associado, sem garantia alguma, que a reconciliação significa felicidade. "O delírio dos indigentes é gerador de acontecimentos, fonte de história: uma multidão de arrebatados que querem outro mundo, aqui e agora." (CIORAN, 1994, p. 103). A utopia é alimento para aqueles que enfrentam dificuldades físicas, sociais e existenciais, e dela esperam a salvação individual e coletiva. As crenças em uma soteriologia universal capaz de trazer a história, a unificação e o conhecimento, ou, pelo menos, a justiça ou a ordem, estabelecida como uma unidade incorruptível. O que nunca se questiona são as consequências de tais empreendimentos ou, no mínimo, qual a garantia. Tais empreendimentos então seriam a reconciliação entre indivíduo e mundo, nisto estariam resolvidas as angustias humanas perante as injustiças da realidade. A utopia é a promessa de um paraíso na história, mas que não podem ser garantidas de fato, nem por meio da revolução. Por mais que se tenha dito que o socialismo era científico, ele, ainda, pertencia ao movimento religioso, falava de uma salvação incapaz de provar, sua força motriz era a esperança de adoção para uma humanidade órfã e sofredora. E como, então, ela é capaz de justificar todo genocídio ocorrido? Aqueles que aderem à utopia não são maus, mas não percebem que:
“A utopia é, por essência, antimaniqueísta, hostil a anomalia, ao disforme, ao irregular, tende para o fortalecimento do homogêneo, do modelo, da repetição e da ortodoxia. Mas a vida é ruptura, heresia, abolição das normas da matéria. E o homem, em relação a vida, é heresia em segundo grau, vitória do individual, do capricho, aparição aberrante, animal cismático que a sociedade [...] pretende conduzir ao caminho reto." (CIORAN, 1994, p. 107)

É possível argumentar que não é inteiramente a passagem para um historicismo que levou a tais acontecimentos e justificações do mesmo, porém, se não perder a linha do raciocínio, é possível perceber que o problema está exatamente quando houve a passagem para uma noção puramente Histórica do homem (excluindo toda noção metafísica) quando se viu a história como instrumento de unidade, instrumento capaz de resolver todo antagonismo da humanidade.

Os movimentos transformaram Marx em um porta-voz capaz de guiar, através da dialética, a resolução última de todas as instâncias, chegaríamos, então, à Cidade perfeita. O problema ocorre que se não há dialética não há História, é impossível, se não houver sempre movimento, não há dialética sem antagonismo, por tal motivo, a utopia é sempre um fracasso. A utopia pretende a perfeição e a racionalidade total das causas humanas, da extinção de classes, produção 
material a liberdade total, por outro lado, se esquecem de que a História não pode ser instrumento de previsões científicas, como queria o socialismo científico, visto que não existe racionalidade na história.

Ou seja, a História é formada pelas ações humanas, por suas vontades, circunstâncias e todas as consequências e interpretações arrancadas dos acontecimentos. Se a história acontece irracionalmente e seu movimento é dialético, $\log$ a resolução dos antagonismos da humanidade se torna um empreendimento destinado ao fracasso. Fracasso capaz de justificar assassinatos e massa, ou seja, o antagonista é sempre visto como uma praga na lavoura e, por isso, precisa ser exterminada.

\section{A traição}

Há, em grande parte do senso comum, e também no acadêmico, o discurso que propaga uma idealização romântica da utopia. Tal discurso se compromete com a argumentação que a utopia é aquilo que permite ao ser humano continuar vivendo e buscando algo maior que ele mesmo. Já vimos então que toda utopia tem em si um caráter totalitário e misturada à ideologia consagrasse um movimento unilateral onde a maldade do mundo deve ser eliminada para efetivação do desejo de unidade, da plena reconciliação humana. E é exatamente aí que reside o erro, de forma mais clara, podemos questionar que é exatamente porque o ser humano, através da utopia, ultrapassa a si mesmo, vive por algo maior que a própria humanidade, que sua luta então se torna infecunda e sua vida uma negação. Negação disfarçada de afirmação. Vive-se na "Esperança de uma outra vida que é preciso "merecer", ou truque daqueles que vivem não pela vida em si, mas por alguma grande ideia que a ultrapassa e a trai. " (CAMUS, 2012, p. 22).

A traição, dita por Camus, é quando damos as ideias ânimo e as inserimos no tempo, ou seja, acreditamos ser possível transformar o mundo totalmente através de uma ideia e logo tal ideia se torna dogma para a salvação, trazendo-as então ao campo da concretude queremos torná-las domínio e realização plena. Isso se mostra nosso esquecimento que o plano da ideia é diferente do plano real. Não há degradação no plano ideal. Viver por uma grande ideia de salvação torna tudo insustentável, pois seus valores se tornam menos humanos e grandiosos demais para nossa insignificância. Nosso desejo de unidade é, também, uma característica de dominação. Vivemos totalmente abandonados num mundo de degradação buscamos então 
dominar todos os aspectos possíveis, seja através da técnica, da política ou da filosofia. Lógico que é possível dizer que as ideias são puramente humanas, nascidas das mentes humanas, como é viável então dizem que pertencem a um plano diferente? Ora, A abstração é o fundamento da ideia. As ideias têm sua importância e efetividade para nossa condição, aliás, elas nos fazem humanos, contudo há uma discrepância quando se tenta tornar a ideia totalmente concreta, pois, por mais sofisticada que seja a ideia, não alcança toda mudanças, todo devir do mundo humano. Tais colocações levamnos a um beco tortuoso onde parece não ter saída, demos de cara com um muro. Será possível então pensar em uma ética, ou política sem a necessidade de uma utopia? Será a moralidade simples fruto de uma convenção ou acaso? Qual o papel da filosofia então? Pois, bem talvez a saída seja pular o muro ou demoli-lo.

Talvez uma das grandes percepções de que a História é irracional foi com Schopenhauer em $O$ mundo como Vontade e Representação, porém sua resolução ao problema é voltada para o ascetismo, até porque se trata de uma metafísica, e nós iremos trabalhar em outra perspectiva. Devido à irracionalidade da História e sua movimentação só através da dialética, um movimento sem fim, iremos buscar um resposta que não traia o ser humano que não seja uma grande ideia, mas apenas algo do âmago humano, o sentimento. $\mathrm{O}$ sentimento de revolta.

Revolta é um humanismo

O que é a revolta? Revoltar-se é exigir um valor, tomar nota de uma situação que oprime e esmaga a dignidade humana. Camus, em O homem Revoltado, descreve que um escravo, até dado momento, suporta todas as pressões que são lançadas sobre ele, porém há um ponto, uma linha, onde tudo aquilo se torna demasiadamente absurdo, torna-se inaceitável que se sacrifique a dignidade assim, logo o escravo se revolta e exige que as condições que lhe oprimem sejam diferentes, repensadas pelo seu senhor. A revolta reclama então algum valor de bem referente à dignidade humana. $\mathrm{O}$ revoltado não nega o senhor como um existente, contudo, reivindica a situação que o senhor lhe impõe. A revolta não é vontade de aniquilação de outros. Revoltar é reivindicar de valor cabível a todos os seres humanos, neste ponto a revolta é transcendente. Então " $\mathrm{Na}$ revolta, o homem se transcende no outro, e, desse ponto de vista, a solidariedade humana é metafísica.” (CAMUS, 2011, p. 29). 
A grande revelação de um valor humano que, transcendendo seu nascimento individual, se mostra legítimo no momento que foi capaz de abarcar toda humanidade. No movimento do sentimento de absurdo $^{2}$, portanto, se não há sentido na vida, no significante a uma teleologia, predestinação, ou fim último da História. Há, por outro lado, valores que emanam dos nossos sentimentos de acordo com as situações do mundo, situações que outros, ou o mundo, impõem a nós ou situações que num mundo formado onde há injustiças e a morte como fatos captados pela consciência.

$\mathrm{Na}$ experiência do absurdo, o sofrimento é individual. A partir do movimento de revolta, ele ganha a consciência de ser coletivo, é a aventura de todos. $\mathrm{O}$ primeiro avanço da mente que se sente estranha é, portanto, reconhecer que ela compartilha esse sentimento com todos os homens, e que a realidade humana, em sua totalidade, sofre com esse distanciamento em relação a si mesmo e ao mundo. (CAMUS, 2011, p. 35)

Exige um bem legítimo, reconhecido por todos, daí, por tal motivo, logo revolta não se guia por sistemas abstratos de vida perfeita ou que apontam um modelo a ser seguido; uma vida além

2 Sentimento Absurdo é a contraposição da consciência com o mundo. Sentimento de que se é estrangeiro a própria vida. A vida é sem sentido, por isso há possibilidade infinitas de felicidade, portanto deve-se buscar valores que afirmem a vida e proporcionem possibilidades de liberdade. Ler $O$ mito de Sísifo. desta aqui. A revolta reclama algo pra ser feito no agora. Não se trata de tornar-se livre de algo, mas tornar-se livre para algo. Nenhuma teoria política que aponte um modelo certo, como uma verdade absoluta, e que não é fundando em valores reclamados pela revolta pode ser então representante legítimo de todas as condições humanas. Quando se almeja aquilo que deveria ser logo se esquece de como as coisas são e, então, há, também, nisso um salto de fé. A revolta é sempre fundada de como as coisas são e como elas podem ser a partir de como as coisas são, ou seja, ela não é abstração dos fatos e não busca a aniquilação das dicotomias ou de um mal. Não há espaço para maniqueísmo no sentimento de revolta, para ela é necessário que sempre exista tensão. $\mathrm{O}$ revoltado não deslumbra a salvação ou perfeição do mundo, até dado momento aguenta as injustiças e as opressão, é sempre lembrando que em algum momento pode se tornar insustentável e, deste ponto, exigir algum valor. "Uma das poucas posturas filosóficas coerentes é a revolta, o confronto perpétuo do homem com sua escuridão.” (CAMUS, 2012, p. 66).

O Revoltado não se guia pelo messianismo do fanatismo, apenas pela sensibilidade que foi capaz de mobilizar e se tornar universal a todos os seres humanos. A revolta é de uma natureza categórica onde lutas e exigências de 
valores mostram-se motivos e necessidades de liberdade humana. De respeito a sua dignidade humana e de apelo a sua felicidade. A revolta faz parte da dialética da história sempre moldando e suscitando novas descobertas no campo da ética. Uma busca eterna pela liberdade sabendo que a liberdade e o fim do sofrimento total serão impossíveis. É no sentimento de revolta que se encontra o humanismo, pelo ato da revolta em si ou pela identificação da revolta de outros, ou seja, a revolta quando exige um valor universal necessário para vivência humana é sempre capaz de indicar aquilo que oprime o ser humano. Por exemplo, a fome, a paz, melhorias públicas e etc. Sem negar as situações erradas ou se afundar na nostalgia de uma Cidade perfeita o sentimento de revolta apenas exige aquilo que lhe falta. Pois todo revoltado sabe que "A essência da vida social é a injustiça. Portanto como aderir a uma doutrina social e política?" (CIORAN, 2012, p. 112) A revolta, para não se cair nas garras messiânicas da revolução, mantém desdém a esperança de um mundo melhor e seu humanismo é sempre contra qualquer opressão e miséria humana. Tudo aquilo que corrompe a liberdade e atente contra a vida. "Não admito uma revolta relativa diante das injustiças, mas apenas uma revolta eterna, pois eterna é a miséria humana da humanidade." (CIORAN, 2012, p. 113).
Podemos concluir que a revolta é o verdadeiro sentimento humano capaz de guiar um humanismo não esperançoso, mas que se mantém contínuo na história. A sua essência é antagonista, é dialética, visto que diversos valores mudam de acordo com as exigências e mudança da vida social logo é necessário que a revolta não busque engessar o mundo, apenas se mostra capaz de tocar a sensibilidade universalmente. $\mathrm{O}$ verdadeiro humanismo reside em manter a revolta contra toda injustiça e miséria, contra tudo aquilo que diga "eu sou o caminho", pois ao conhecer apenas um caminho todos os outros são vistos como maus. E no sentimento de revolta é preciso que se mantenha a inocência de que a humanidade é um eterno descobrimento de si mesma, um esforço inútil sem destino último. A vida perfeita e reconciliada é impossível, mas aquilo que nos fará prosperar é a solidariedade através da revolta. Nenhum messias político ou religioso é dono da verdade (ou a própria verdade). É na solidariedade nascida da revolta que o desejo de unidade deve se debruçar.

\section{Referências Bibliográficas}

CAMUS, Albert. O Mito de Sísifo. Tradução: Ari Roitman e Paulina Watch. $9^{a}$ ed. Rio de Janeiro: Record, 2012. 
CAMUS, Albert. $O$ Homem Revoltado. Tradução: Valerie Rumjanek. $8^{a}$ ed. Rio de Janeiro: Record, 2010.

CIORAN, Emil. Nos cumes do desespero. Tradução: Fernando Klabin. São Paulo: Hedra, 2012.

CIORAN, Emil. Breviário de Decomposição. Tradução: José Thomaz Brum. Rio de Janeiro: Rocco, 2011.

CIORAN, Emil. História e Utopia. Tradução: José Thomaz Brum. Rio de Janeiro: Rocco, 1994.

FLEISCHER, Margot. Filósofos do século $X X$. São Leopoldo: Editora UNISINOS, 2004.

GUIMARÃES, Eduardo. As dimensões do homem: mundo, absurdo e revolta. Rio de Janeiro: Paz e Terra, 1971.

MACHADO, Patrícia Oliveira. Absurdo, Revolta, Ação: Albert Camus. Brasília. 2010. 106. Mestrado. Programa de Pós-Graduação em Filosofia, Universidade de Brasília, 2010.

MARX; Karl. ENGELS, Friedrich. Manifesto do Partido Comunista. Tradução: Pietro Nassetti. São Paulo: Martin Claret, 2000.

MOUNIER, Emmanuel. A esperança dos desesperados. Tradução: Naumi Vasconcelos. Rio de Janeiro: Paz e Terra, 1972.

NIETZCHE, Friedrich. Além do bem e do mal. Tradução: Renato Zwick. Porto Alegre, RS: L\&PM, 2009.
PIMENTA, Danilo Rodrigues. A criação absurdo segundo Albert Camus. Brasília. 2010. 120. Mestrado. Instituto de Filosofia da Arte e Cultura, Universidades Federal de Ouro Preto, 2010.

RAMOS, Flamarion Caldeira. Absurdo e revolta em Albert Camus. Revista Integração, São Paulo, Ano XIII, Abr/Mai/Jun, $\mathrm{n}^{\mathrm{o}}$ 49, $2007 . \quad$ 177-184. Disponível em: <http://www.usjt.br/prppg/revista/integraca o/integracao_49.php> acesso em: $20 \mathrm{de}$ Julho, 2015.

SAMPAIO, Leandson Vasconcelos. Filosofia, Jornalismo e Dramaturgia: Ética, Engajamento e Responsabilidade em Albert Camus. Fortaleza. 2015. 64. Mestrado. Programa de Pós-Graduação em Filosofia, Fortaleza, 2015.

SCHOPENHAUER, Arthur. $O$ mundo como vontade e representação. Tradução: M. F. Sá correia. Rio de Janeiro: Contraponto, 2001. 